\title{
Randomised crossover trial of rate responsive Activitrax and conventional fixed rate ventricular pacing
}

\author{
DAVID PLIPKIN, $\ddagger$ NIGEL BULLER, $\dagger$ MICHAEL FRENNEAUX, \\ LESLEY LUDGATE, $\dagger$ TRUDY LOWE, STUART C WEBB, * \\ DENNIS M KRIKLER*
}

From the ${ }^{\star}$ Division of Cardiovascular Diseases, Royal Postgraduate Medical School, Hammersmith Hospital, and $\dagger$ National Heart Hospital, London

SUMMARY Atrial tracking pacemakers may improve exercise capacity and symptoms because they maintain atrioventricular synchrony and preserve the physiological response of heart rate to exercise. A rate responsive pacemaker which reacts to physical activity may be effective in patients with sinus node disease who are unsuitable for VDD pacing. At least three months after implant a double blind randomised short and long term crossover study was performed in ten patients with complete heart block: block was present at rest and during exercise on a modified Bruce protocol. Symptoms were assessed on a visual analogue scale and exercise capacity (maximal oxygen consumption and anaerobic threshold) was measured during rate responsive (peak rate $125 / \mathrm{min}$ ) and conventional fixed rate (VVI) pacing $(70 / \mathrm{min})$. One month after randomisation treadmill exercise was performed. The mode was then changed to the other pacing mode and exercise was repeated three hours later. After another month the process was repeated but in the reverse order. During long term assessment there was subjective improvement in the sensation of breathlessness with rate responsive pacing. During short term assessment maximal oxygen consumption increased and the benefit was maintained during long term rate responsive compared with long term VVI pacing; oxygen consumption at the anaerobic threshold was similarly improved.

Activity detecting rate responsive pacing is better than fixed rate ventricular pacing in patients with complete atrioventricular block.

Double blind crossover studies have shown that the occurrence or severity of subjective symptoms or both are significantly lower during atrial synchronised ventricular pacing than during fixed rate VVI pacing, ${ }^{12}$ but there is no agreement about the magnitude of the improvement in exercise capacity. Atrial synchronised ventricular pacing can only ensure a physiological ventricular rate response if the atrial rate is a good indicator of circulatory demand. Patients with sinus bradycardia, sinus arrest, or drug resistant atrial tachycardia are therefore less suitable candidates for atrial synchronised ventricu-

†Present address: Cardiology Department, Royal Free Hospital, Pond Street, London NW3 2QG.

Requests for reprints to Dr Dennis M Krikler, Hammersmith Hospital, Ducane Road, London W12 OHS.

Accepted for publication 9 July 1987 lar pacing. The Activitrax pacemaker (Medtronic) varies the pacing rate in response to the level of physical activity as detected by a sensor bonded to the inside of the case of the pulse generator. Recent short term studies have suggested that it was better than fixed rate VVI pacing ${ }^{34}$ and a multicentre study demonstrated an improvement in exercise duration during Activitrax pacing. ${ }^{5}$

The purpose of this study was to compare the effect of Activitrax rate responsive pacing with that of conventional fixed rate VVI pacing on symptoms and exercise capacity during a randomised short term and long term crossover study. Exercise capacity was assessed by measuring maximal oxygen consumption and anaerobic threshold during treadmill exercise: these measurements are reproducible (coefficient of variation $8 \%$ ) and seem to provide the most objective indication of exercise capability. ${ }^{67}$ 


\section{Patients and methods}

\section{PATIENT SELECTION}

We studied 10 patients (mean age 50 years (range 30-75)) with complete anterograde atrioventricular block at rest and during exercise. Nine patients had retrograde atrioventricular block at rest. Exercise capacity was limited only by dyspnoea or fatigue in all patients. A ventricular rate responsive pacemaker (Activitrax, Medtronic) was implanted in all patients 3-6 months before the start of the study. The underlying cardiac disease was dilated cardiomyopathy (three patients), previous aortic valve surgery (two patients), idiopathic atrioventricular block (two patients), ablation of the atrioventricular node for uncontrolled atrial fibrillation (one patient), hypertension (one patient), and primary pulmonary hypertension with right heart failure (one patient). Patients were excluded from the study if they had suffered a myocardial infarction during the previous six months or had a history suggestive of myocardial ischaemia or pulmonary disease.

\section{TRIAL DESIGN}

Treadmill exercise capacity was assessed on a modified Bruce protocol by measuring maximal oxygen consumption and anaerobic threshold by computerised mass spectrometric analysis of mixed expired air. ${ }^{6}$ Before entry to the study patients repeated practice exercise tests until symptom limited maximal oxygen consumption differed by less than $5 \%$ on two consecutive exercise tests. The exercise tests were performed at the same time of day for each patient. The pacemaker mode was randomised to either fixed rate mode (VVI $70 / \mathrm{min}$ ) or to rate responsive mode. During the study the patient and the doctor supervising the exercise test were not told what pacemaker mode was being used. In rate responsive mode the back up rate was $70 / \mathrm{min}$ and the upper limit was $125 / \mathrm{min}$. The rate response mode and the activity threshold were altered so that during a practice test at maximal exercise capacity the upper rate limit was reached. One month later exercise capacity was assessed in the original randomised mode ("long term mode"). The alternative mode was reprogrammed and the patients reexercised three hours later ("short term mode"). Similarly, one month later the patient was exercised (alternative long term mode) and re-exercised three hours later in the initial pacing mode (short term mode). Symptoms were assessed at the end of each month of long term mode pacing by a questionnaire completed by the patient. The questionnaire contained 24 questions relevant to the symptoms of breathlessness, fatigue, and psychological state. The questionnaire was developed at McMaster Univer- sity (available on request from DPL). Each question was on a separate sheet of paper and the patient was requested to make a mark on a visual analogue scale $10 \mathrm{~cm}$ in length. The distances of all the marks for each category of questions were summed so that a maximum of 80 indicated maximum symptoms. Left ventricular fractional shortening was assessed by cross sectional echocardiography performed in the VVI mode.

\section{STATISTICAL ANALYSIS}

Because data were not normally distributed $95 \%$ confidence limits are not quoted. Differences in symptoms and exercise capacity were thus assessed by the Wilcoxon matched pairs rank sum test. Results are quoted as mean and interquartile range (that is the range containing the middle $50 \%$ of the sample values).

\section{Results}

Mean left ventricular fractional shortening was $28 \%$ (range $10-40 \%$, normal 23-37\%). Exercise capacity was significantly greater during rate responsive pacing (table 1, figs 1 and 2). During short term assessment the mean maximal oxygen consumption $(\mathrm{ml}$ $\mathrm{kg} / \mathrm{min}$ ) increased and the benefit (compared with long term VVI pacing) was maintained during long term rate responsive pacing $(18(1)$ and $19(1)$ vs $16(1)$ respectively $(p<0.02)$ ) This was a mean improvement of $14 \%$ (increased, eight patients; unchanged, one patient; decreased, one patient). The anaerobic threshold was reached in seven patients. Oxygen consumption and the anaerobic threshold also improved on rate responsive pacing $(14(1)$ and 14 (1) vs $12(1)(\mathrm{p}<0.04)$ (increased in six patients, unchanged in one patient). The subjective sensation (out of a maximum score of $\mathbf{8 0}$ ) for symptoms of breathlessness, fatigue, and psychological state were less in rate responsive than in VII pacing, but the difference between the two pacing modes was significant only for the symptom of breathlessness $(\mathrm{p}<0.05)$ (eight patients improved, one remained unchanged, and one deteriorated).

\section{Discussion}

The problem of impaired exercise capacity associ- $\omega$ ated with chronotropic incompetence has been approached in several ways. Atrial synchronised $\varrho$ ventricular pacing reduces the occurrence and sever- $\Phi$ ity of subjective symptoms more than fixed rate VVI $\stackrel{?}{\rightarrow}$ pacing. The magnitude of the objective improvement is debatable and may reflect the aware- $\frac{O}{\mathbb{D}}$ ness of the pacing mode by the doctor supervising $\stackrel{\bigcirc}{\Phi}$ the exercise test. ${ }^{128}$ Improvement in bicycle work- $\stackrel{\mathbb{Q}}{\triangle}$ 
le Measurement of maximal oxygen consumption $\left(\dot{V} \mathrm{O}_{2}\right.$ max), anaerobic threshold, and visual analogue scale scores (maximum score during short term and long term VVI and rate responsive pacing (VVI-Act)

\begin{tabular}{|c|c|c|c|c|c|c|c|c|c|c|c|c|c|c|c|}
\hline \multirow{3}{*}{$\begin{array}{c}\text { Age } \\
\text { Io }(y r)\end{array}$} & \multirow[b]{3}{*}{ Diagnosis } & \multicolumn{4}{|c|}{$\dot{V} \mathrm{O}_{2} \max (\mathrm{ml} / \mathrm{kg} / \mathrm{min})$} & \multicolumn{4}{|c|}{$\begin{array}{l}\text { Anaerobic } \\
\text { threshold }(\mathrm{ml} / \mathrm{kg} / \mathrm{ml})\end{array}$} & \multicolumn{6}{|c|}{ Visual analogue scale } \\
\hline & & \multicolumn{2}{|l|}{ Long } & \multicolumn{2}{|l|}{ Short } & \multicolumn{2}{|l|}{ Long } & \multicolumn{2}{|l|}{ Short } & \multicolumn{2}{|c|}{$S O B$} & \multicolumn{2}{|c|}{ Fatigue } & \multicolumn{2}{|c|}{ Psychological } \\
\hline & & \multicolumn{2}{|c|}{$V V I-A c t V V I$} & \multicolumn{2}{|c|}{$V V I-A c t V V I$} & \multicolumn{2}{|c|}{$V V I-A c t V V I$} & \multicolumn{2}{|c|}{$V V I-A c t V V I$} & \multicolumn{2}{|c|}{$\overline{V V I-A c t} V V I$} & \multicolumn{2}{|c|}{$V V I-A c t V V I$} & \multicolumn{2}{|c|}{$\overline{V V I-A c t V V I}$} \\
\hline $\begin{array}{l}30 \\
45 \\
30 \\
55 \\
40 \\
56 \\
62 \\
63 \\
62 \\
75\end{array}$ & $\begin{array}{l}\text { PHT } \\
\text { IDC } \\
\text { AVR } \\
\text { Idio } \\
\text { AVR } \\
\text { ABL } \\
\text { HT } \\
\text { IDC } \\
\text { IDC } \\
\text { Idio } \\
\text { Mean }\end{array}$ & $\begin{array}{l}17 \\
19 \\
29 \\
22 \\
14 \\
19 \\
18 \\
15 \\
16 \\
18 \\
18 \cdot 7^{\star}\end{array}$ & $\begin{array}{l}14 \\
17 \\
24 \\
17 \\
12 \\
16 \\
16 \\
17 \\
16 \\
15 \\
16 \cdot 4\end{array}$ & $\begin{array}{l}15 \\
20 \\
27 \\
21 \\
13 \\
16 \\
16 \\
18 \\
17 \\
18 \\
18 \cdot 1^{\star}\end{array}$ & $\begin{array}{l}13 \\
18 \\
24 \\
17 \\
13 \\
15 \\
16 \\
14 \\
15 \\
17 \\
16 \cdot 2\end{array}$ & $\begin{array}{l}15 \\
15 \\
16 \\
16 \\
11 \\
\text { NR } \\
\text { NR } \\
12 \\
13 \\
\text { NR } \\
14 \cdot 0 \dagger\end{array}$ & $\begin{array}{l}12 \\
13 \\
15 \\
14 \\
10 \\
\mathrm{NR} \\
\mathrm{NR} \\
12 \\
12 \\
\mathrm{NR} \\
12 \cdot 6\end{array}$ & $\begin{array}{l}15 \\
13 \\
15 \\
21 \\
11 \\
\text { NR } \\
\text { NR } \\
13 \\
12 \\
\text { NR } \\
14 \cdot 0 \ddagger\end{array}$ & $\begin{array}{l}13 \\
12 \\
15 \\
17 \\
10 \\
\mathrm{NR} \\
\mathrm{NR} \\
11 \\
13 \\
\mathrm{NR} \\
13 \cdot 2\end{array}$ & $\begin{array}{r}18 \\
8 \\
43 \\
28 \\
46 \\
55 \\
15 \\
25 \\
18 \\
10 \\
27 \S\end{array}$ & $\begin{array}{l}20 \\
39 \\
59 \\
28 \\
48 \\
45 \\
24 \\
38 \\
20 \\
63 \\
38\end{array}$ & $\begin{array}{r}33 \\
38 \\
45 \\
8 \\
52 \\
91 \\
7 \\
30 \\
10 \\
14 \\
33\end{array}$ & $\begin{array}{r}31 \\
68 \\
81 \\
28 \\
50 \\
76 \\
9 \\
41 \\
11 \\
62 \\
46\end{array}$ & $\begin{array}{r}24 \\
21 \\
38 \\
21 \\
31 \\
55 \\
0 \\
15 \\
7 \\
12 \\
22\end{array}$ & $\begin{array}{r}26 \\
13 \\
51 \\
30 \\
24 \\
49 \\
3 \\
17 \\
7 \\
55 \\
28\end{array}$ \\
\hline
\end{tabular}

not reached; $\mathrm{VO}_{2}$ max, maximal oxygen consumption; SOB, breathlessness; PHT, pulmonary hypertension; AVR, after aortic valve replacement; , idiopathic; ABL, after atrioventricular node ablation; HT, hypertension; IDC, idiopathic dilated cardiomyopathy.

$=0.02$ compared with chronic VVI; $\nmid p<0.04$ compared with chronic VVI; $\ddagger p<0.03$ compared with chronic VVI; $\$ p<0.05$ compared with inic VVI.

load in VDD as compared with VVI mode has been reported as $27^{1}$ and $14 \% .^{2}$ Some patients may have recognised the pacing mode by feeling their pulse, and this could have influenced the measurement of maximal exercise capacity. Although our patients were not informed of the pacing mode at any time, it was impossible to prevent an intelligent patient from deducing it. To minimise observer bias one physician and a cardiac technician supervised the exercise tests; the physician remained unaware of the pacing mode and the technician observed the electrocardiogram during the test.

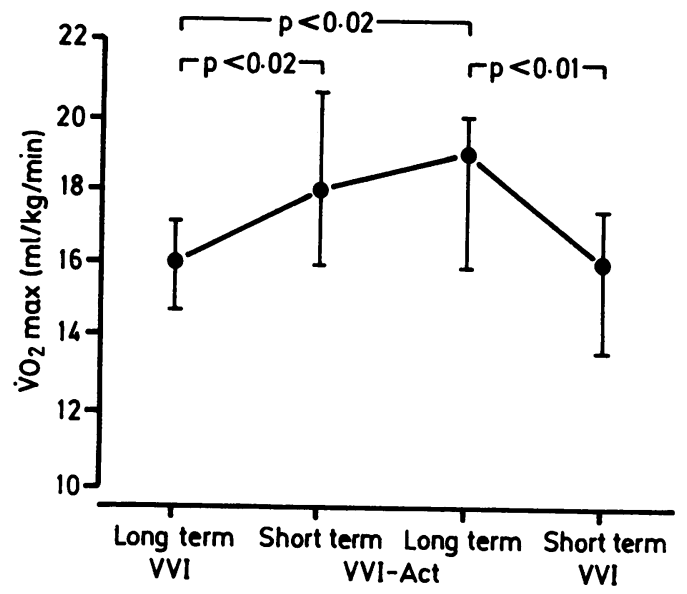

Fig 1 Changes in maximal oxygen consumption $\left(\dot{V} \mathrm{O}_{2}\right.$ max) during short term and long term $V V I$ and rate responsive (VVI-Act) pacing. Bars represent interquartile ranges.
Exercise capacity was assessed by measuring maximal oxygen consumption and anaerobic threshold. Assessment of maximal oxygen consumption is precise and reproducible; but it is symptom limited and therefore affected by patient motivation and not totally objective. The physiological meaning of an "anaerobic threshold" is complex but its measurement provides a more objective assessment of exercise capacity. ${ }^{67}$ Maximal oxygen consumption and anaerobic threshold increased during short term and long term rate responsive pacing. A recent report demonstrated an improvement in maximal oxy-

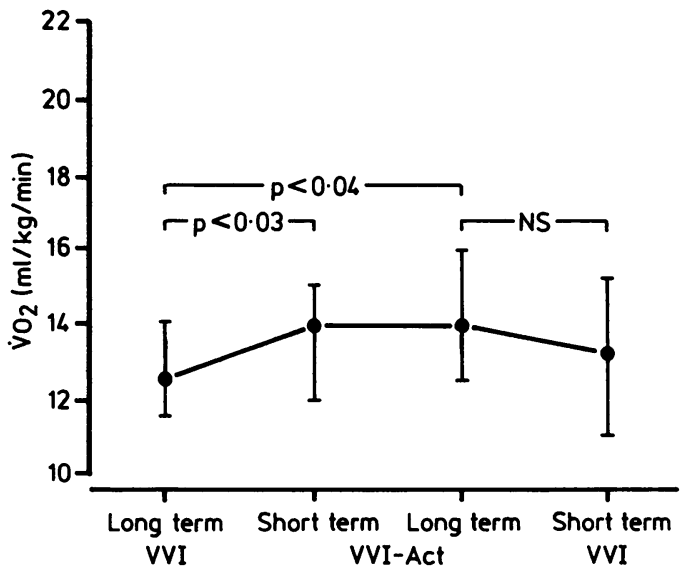

Fig 2 Changes in anaerobic threshold during acute and chronic VVI and rate responsive (VVI-Act) pacing ( 7 patients). Bars represent interquartile ranges. $\dot{V} \mathrm{O}_{2}$, oxygen consumption at the anaerobic threshold. 
gen consumption and anaerobic threshold with activity responsive pacing. ${ }^{4}$ This short term study included patients in whom there was anterograde conduction through the atrioventricular node during exercise. We excluded such patients from our study because the inherent capacity for a rise in heart rate would have interfered with our objectives. The fact that our patients showed a smaller mean rise in maximal oxygen consumption cannot be explained by this exclusion, but may reflect their older age.

Many patients do not exercise to their maximal capacity and it is reassuring that the present study confirms the impression that subjective symptoms are improved by rate responsive pacing. Rate responsive pacing reduced the symptoms of breathlessness and fatigue, and, interestingly, improved psychological symptoms, though only the effect on the sensation of breathlessness reached statistical significance. Though Humen et al demonstrated an improvement in anaerobic threshold but not maximal oxygen consumption in six patients undergoing rate responsive compared with VVI pacing, ${ }^{9}$ exercise capacity in their subjects was limited by factors unrelated to cardiovascular performance, such as claudication or arthritis.

Clearly there is an advantage in having an adequate increase in heart rate in response to exercise. A normal atrioventricular sequence may augment cardiac output at rest by about $25 \%,{ }^{10}$ but during exercise the rate increase may be more important. ${ }^{8}$ Haemodynamic function during exercise has been compared in patients during VDD and VVI pacing at a matched heart rate. ${ }^{1112}$ In the first study cardiac output was $8 \%$ higher in the VDD mode, whereas in the second study there was no difference between the two modes. As these studies cannot exclude atrioventricular synchrony occurring by chance the role of atrial contribution to the cardiac output response to exercise cannot be fully assessed. We are unaware of any comparison of VDD and rate responsive pacing.

A dual chamber pacemaker is more complex to implant and program than a rate responsive pacemaker and is not suitable for all patients: some may need an alternative form of rate responsiveness pacing. While other sensors can measure the QT interval, ${ }^{13}$ respiratory rate, ${ }^{14}$ mixed venous oxygen saturation, ${ }^{15}$ and $\mathrm{pH},{ }^{16}$ we decided to evaluate the activity sensing pacemaker, which also provides a physiological heart rate response to exercise, and offers improved effort tolerance and symptomatic improvement when compared with fixed rate ventricular pacing. It is simple to implant and program, and may sometimes obviate the need for dual chamber pacing, particularly in those patients with atrioventricular block and poorly controlled atrial tachycardias or sinus node disease. Our study demonstrates its advantage over VVI pacing and thus suggests its usefulness in an important proportion of $C$ patients with heart block.

We thank Medtronic Inc for financial support.

\section{References}

1 Perrins EJ, Morley CA, Chan SL, Sutton R. Random- §ొ ised controlled trial of physiological and ventricular $\vec{O}$ pacing. Br Heart J 1983;50:112-7.

2 Kristensson BE, Arnman K, Smedgard P, Ryden L. Physiological versus single-rate ventricular pacing: a double-blind cross-over study. PACE 1985;8:73-84.

3 Ryden L, Smedgard P, Kruse I, Anderson K. Rate responsive pacing by means of activity sensing. Stimucoeur 1984;12:181-4.

4 Benditt DG, Mianulli M, Fetter J, et al. Singlechamber cardiac pacing with activity initiated chronotropic response: evaluation by cardiopulmonary exercise testing. Circulation 1987;75:184-91.

5 Chevalier PA, Murtaugh RA. Rate responsive pacing: improved exercise performance with an activity sensing pacemaker-a multicenter study [Abstract]. Circulation 1985;72(suppl III):432.

6 Lipkin DP, Perrins J, Poole-Wilson PA. Respiratory gas exchange in the assessment of patients with impaired ventricular function. $\mathrm{Br}$ Heart $J$ 1985; 54:321-8.

7 Lipkin DP, Bayliss J, Poole-Wilson PA. The use of a submaximal exercise to predict maximal exercise capacity in patients with heart failure. Eur Heart $J$ 1985;6:829-33.

8 Ryden L, Kristensson BE. Rate responsive pacing: $\AA$ effects on hemodynamics, exercise tolerance and sub- $\overrightarrow{\vec{B}}$ jective feeling of well being. In: Zipes DP, Jalife J, $\frac{0}{3}$ eds. Cardiac electrophysiology and arrhythmias. Orlando, Florida: Grune and Stratton, 1985:513-22.

9 Humen DP, Kostuk WJ, Klein GJ. Activity-sensing, rate responsive pacing: improvement in myocardial performance with exercise. PACE 1985;8:52-9.

10 Samet P, Bernstein WH, Levine S. Significance of the atrial contribution to ventricular filling. Am J Cardiol 1965;16:195-200.

11 Karlof I. Haemodynamic effect of atrial triggered versus fixed rate pacing at rest and during exercise in complete heart block. Acta Med Scand 1975; 197:195-206.

12 Ausubel K, Steingart RM, Shimshi M, Klementowicz $P$, Furman S. Maintenance of exercise stroke volume $N$ during ventricular versus atrial synchronous pacing: 5 role of contractility. Circulation 1985;72:1037-43.

13 Donaldson RM, Fox KM, Rickards AF. The initial N experience with a physiological rate responsive $O$ pacemaker. $\mathrm{Br}$ Med J 1983;286:667-71.

14 Rossi P, Plicchi G, Canducci G, Rognoni G, Aina F. Respiration as a reliable physiological sensor for con- $\mathbb{Q}$ trolling cardiac pacing rate. Br Heart $J$ 1984;51:7-14. ?

15 Wirtzfeld A, Heinze R, Stanzl K, Hoekstein K, Alt E, $\frac{T}{-}$ Liess HD. Regulation of pacing rate by variations of mixed venous oxygen saturation. PACE 1984; 7:1257-62.

16 Contini C, Papeschi G, Ricci D, Strata G, Pauletti M. $\mathrm{pH}$ changes in chronic pacemaker pocket. A new means of increasing rate during exercise. Preliminary results [Abstract]. PACE 1980;3:366. 